\title{
Avaliação de milhos de diferentes densidades para frangos de corte ${ }^{1}$
}

\author{
Cynthia Siqueira Silva², José Fernando Machado Menten², Ana Beatriz Traldi², Julieta \\ Santarosa ${ }^{2}$, Patrícia Watanabe Zanin Pereira ${ }^{2}$
}

\author{
1 Pesquisa financiada pela FAPESP. \\ 2 Departamento de Zootecnia, Escola Superior de Agricultura “Luiz de Queiroz", Universidade de São Paulo.
}

RESUMO - O trabalho foi realizado com o objetivo de determinar os valores nutricionais de milhos de quatro qualidades, obtidos por meio de estratificação em mesa densimétrica, para frangos de corte em diferentes idades. Os milhos foram designados como: MDA - milho de densidade alta; MDI - milho de densidade intermediária; MDB - milho de densidade baixa; e MDO milho de densidade original, composto de 25\% de MDA, 50\% de MDI e 25\% de MDB. Três ensaios biológicos foram conduzidos utilizando-se o método tradicional de coleta total de excretas para determinação da energia metabolizável aparente corrigida (EMAn). O primeiro ensaio metabólico foi conduzido com pintos Cobb de 14 a 17 dias, o segundo, com pintos de 25 a 28 dias e o terceiro de 38 a 41 dias de idade. Foram realizadas análises químicas para determinação do perfil nutricional, classificação de grãos segundo a densidade e comparação por meio das estimativas de equações de predição do valor energético. Os valores da EMAn dos milhos de diferentes qualidades (MDA, MDI, MDB e MDO) determinados com frangos na fase inicial foram: 3562, 3382, 3198 e $3357 \mathrm{kcal} / \mathrm{kg}$, para a fase de crescimento: 3576, 3555, 3229 e $3416 \mathrm{kcal} / \mathrm{kg}$ e, para a fase final 3610, 3554,3354 e $3585 \mathrm{kcal} / \mathrm{kg}$, respectivamente. Esses valores comprovam as significativas perdas energéticas dos milhos de mais baixa qualidade e a eficiência da mesa densimétrica em estratificar os grãos. A diferença da EMAn entre as idades das aves sugere melhor eficiência de utilização da energia com o avanço da idade. As equações de predição podem ser utilizadas para estimar o valor energético de milhos, tanto por sua classificação como pelas análises bromatológicas. Entretanto, o erro sistemático associado a cada equação de predição pode comprometer a exatidão de seu valor nutricional.

Palavras-chave: energia metabolizável, equação de predição, mesa densimétrica

\section{Evaluation of corn with different densities for broilers}

\begin{abstract}
The objective of this work was to determine the nutritional value of corn of four different qualities, obtained by stratification in densimetric table, for broilers at different ages. The corns were designed as: MDA - high density corn; MDI - medium density corn; MDB - low density corn and MDO - original density corn, composed of 25\% MDA, 50\% MDI and 25\% MDB. Three biological assays were carried out by using the traditional total excreta collection method for determination of nitrogen corrected apparent metabolizable energy (AMEn). The first metabolism assay was carried out with Cobb chicks at 14 to 17 days of age, the second assay with chicks at 25 to 28 days of age and the third with chicks at 38 to 41 days of age. Chemical analyses were made for determination of the nutritional profile, classification of the grains according to density and comparison by estimates of energy value prediction equations. The values of AMEn of corns of different qualities (MDA, MDI, MDB and MDO) determined in broilers in initial phase were: 3562, 3382,3198 and $3357 \mathrm{kcal} / \mathrm{kg}$ for growth phase and for final phase they were 3576, 3555, 3229 and $3416 \mathrm{kcal} / \mathrm{kg}$ and for the finish phase they were 3610, 3554, 3354 and $3585 \mathrm{kcal} / \mathrm{kg}$, respectively. These results prove that significant energy losses of the lowest quality corns and the efficiency of the densimetric table to stratify the grains. The different AMEN values among ages of the birds suggest better energy use efficiency as age increases. The prediction equations can be used to estimate energy value of corn by its classification and by chemical analyses as well. However, the systematic error associated to each prediction equation can compromise the accuracy of the nutritional value.
\end{abstract}

Key Words: gravity table, metabolizable energy, prediction equation

\section{Introdução}

À medida que os custos dos alimentos aumentam, cresce a necessidade de novas alternativas que atedam às exigências dos animais nas suas diferentes fases de produção. Para isso, deve-se determinar a composição química, a disponibilidade dos nutrientes, a concentração e a disponibilidade de energia dos alimentos. As dietas comumente usadas na avicultura de corte têm milho como principal ingrediente e fonte de energia. No entanto, 
variações significativas são encontradas na composição química e no valor nutricional desse grão, dificultando, assim, a formulação precisa das rações.

As indústrias de rações estão começando a utilizar equipamentos capazes de selecionar grãos de melhor qualidade, como o sistema de pré-limpeza e a mesa gravimétrica. O uso dessas tecnologias permite a utilização de ingredientes da mais alta qualidade na formulação de rações para animais mais jovens.

A mesa densimétrica ou gravimétrica consiste essencialmente de uma armação ajustável, metálica, recoberta por uma superfície porosa de pano (algodão) ou de tela de arame permitindo a passagem do ar através de suas malhas. A coluna de ar produz uma estratificação formando zonas verticais de grãos pesados na parte inferior da camada, os mais leves na superior e os de peso médio na intermediária (Gregg \& Fagundes, 2005).

Para se formular rações mais eficientes e atender adequadamente às exigências nutricionais dos animais, é necessário conhecer com maior precisão, entre outros, os valores energéticos dos alimentos, que podem ser determinados por meio de métodos diretos e indiretos. Os métodos diretos ou convencionais requerem a utilização de uma bomba calorimétrica e ensaios metabólicos, sendo metodologias trabalhosas, demoradas e dispendiosas e, em contrapartida, como método indireto, surgem as equações de predição, que são baseadas na composição proximal dos alimentos e obtidas rotineiramente em laboratórios. Vários pesquisadores têm desenvolvido equações para estimar a energia metabolizável por meio de sua composição proximal (NRC, 1994); porém, existem poucos estudos para validação destas equações. Dessa forma, realizou-se este estudo com o objetivo de determinar da energia metabolizável aparente corrigida (EMAn) de milho de diferentes densidades com frangos de corte em diferentes idades e estimar os valores de EMAn utilizando equações de predição, fazendo inferência entre os valores de EMAn determinados in vivo na fase de crescimento e os determinados por equações com aqueles obtidos por equações de predição publicadas por Janssen et al.(1989), Rodrigues et al. (2001) e por Rostagno et al. (2005), a fim de se verificar a aplicabilidade dessas equações na determinação dos valores energéticos desses alimentos.

\section{Material e Métodos}

O experimento foi conduzido no Setor de Avicultura do Departamento de Zootecnia da Escola Superior de Agricultura “Luiz de Queiroz” (ESALQ).
O milho utilizado neste trabalho foi proveniente de um único plantio e após receber a pré-limpeza, foi segregado em mesa gravimétrica, obtendo milhos de diferentes densidades: MDO - milho de densidade original que é o milho antes da estratificação; MDA - milho de densidade alta; MDI milho de densidade intermediária e MDB - milho de densidade baixa. A mesa foi ajustada para separar aproximadamente $25 \%$ do milho na fração de alta densidade e 25\% na de baixa densidade, ficando o restante na densidade intermediária. Após a estratificação, o milho foi classificado de acordo com o Ministério da Agricultura, Pecuária e do abastecimento (MAPA) em grãos de milho quebrado, fragmentos e impurezas, grãos atacados por fungos e grãos atacados por insetos. Para cada tipo de milho foram determinados: proteína bruta (PB), extrato etéreo (EE), extrativo não-nitrogenado (ENN), fibra bruta (FB), matéria mineral (MM) de acordo com Silva (1990), e em seguida foi estimada a EMAn das de diferentes densidades do milho por meio de equações desenvolvidas por Janssen et al. (1989), Rodrigues et al. (2001) e Rostagno et al. (2005).

Após a segregação, foram determinadas as densidades dos diferentes milhos através de balança de peso hectolitro para construção de uma equação de predição, essas medidas foram realizadas logo após a segregação quando o milho então foi empregado nos ensaios metabólicos e após um período de 16 meses de armazenamento, com intuito de se observar o comportamento de milhos segregados ao longo do tempo.

$\mathrm{EMAn}=36,21 \mathrm{~PB}+85,44 \mathrm{EE}+37,26 \mathrm{ENN}$ (Janssen, 1989)

EMAn $=4281,6-39,97 \mathrm{FDN}(\%)-72,90 \mathrm{MM}(\%)$ (Rodrigues et al., 2001) e

EMp (energia metabolizavel de perdas $)=-0,064+1,62$ milho quebrado $+6,98$ fragmentos e impurezas $+10,06$ milho atacados por fungos $+12,28$ atacados por insetos $+5,87$ ataque por diversas outras causas (Rostagno et al., 2005).

Paralelamente foram conduzidos três ensaios de metabolismo com frangos de corte, para a estimativa dos valores de energia metabolizável, utilizando-se o método tradicional de coleta total de excretas. Cada ensaio de metabolismo correspondeu a uma fase de criação: inicial (14 a 17 dias), crescimento (25 a 28 dias) e final (38 a 41 dias).

Nos três ensaios de metabolismo, foram empregados os mesmos tipos de milho de diferentes densidades (MDA, MDI, MDB e MDO) que substituíram, em proporção idêntica (40\%), parte da dieta referência, à base de milho e farelo de soja. Cada tratamento foi aplicado a quatro repetições, portanto a quatro gaiolas em cada ensaio. A dieta-referência em cada ensaio foi formulada de acordo com as Tabelas Brasileiras (Rostagno et al., 2005) (Tabela 1). 
Tabela 1- Composição das rações experimentais

\begin{tabular}{|c|c|c|c|}
\hline \multirow[t]{2}{*}{ Ingrediente (\%) } & \multicolumn{3}{|c|}{ Dieta-referência } \\
\hline & Inicial & Crescimento & Final \\
\hline Milho & 57,315 & 60,228 & 64,712 \\
\hline Farelo de soja & 35,285 & 31,703 & 27,608 \\
\hline Fosfato bicálcico & 1,836 & 1,691 & 1,538 \\
\hline Calcário & 0,904 & 0,856 & 0,814 \\
\hline Óleo de soja & 3,321 & 4,277 & 0,412 \\
\hline Sal comum & 0,502 & 0,478 & 0,452 \\
\hline DL-metionina (99\%) & 0,269 & 0,245 & 0,240 \\
\hline L-lisina $\mathrm{HCl}(78,4 \%)$ & 0,218 & 0,212 & 0,269 \\
\hline L-treonina $(98,5 \%)$ & 0,066 & 0,055 & 0,075 \\
\hline Cloreto de colina $60 \%$ & 0,080 & 0,060 & 0,040 \\
\hline Suplemento vitamínico ${ }^{1}$ & 0,100 & 0,080 & 0,060 \\
\hline Suplemento mineral ${ }^{2}$ & 0,050 & 0,050 & 0,050 \\
\hline Coxistac $(500 \mathrm{~g} / \mathrm{t})$ & 0,050 & 0,050 & - \\
\hline Halquinol 98\% (50 g/t) & 0,003 & 0,003 & - \\
\hline \multicolumn{4}{|l|}{ Composição calculada } \\
\hline Energia Metabolizável (kcal/kg) & 3050 & 3150 & 3200 \\
\hline Proteína bruta (\%) & 21,14 & 19,73 & 18,31 \\
\hline Metionina digestível (\%) & 0,560 & 0,521 & 0,499 \\
\hline Met+Cis digestível (\%) & 0,844 & 0,791 & 0,755 \\
\hline Lisina digestível (\%) & 1,189 & 1,099 & 1,048 \\
\hline Treonina digestível (\%) & 0,899 & 0,837 & 0,775 \\
\hline Triptofano digestível (\%) & 0,230 & 0,210 & 0,200 \\
\hline Cálcio (\%) & 0,889 & 0,837 & 0,775 \\
\hline Sódio (\%) & 0,218 & 0,208 & 0,198 \\
\hline Fósforo disponível (\%) & 0,449 & 0,418 & 0,386 \\
\hline
\end{tabular}

${ }^{1}$ Quantidade por kg de produto: vit. A - 10.000.000 UI; vit. D3 - 3.000.000 UI; vit. E - $40.000 \mathrm{UI}$; vit. K3 - $3.000 \mathrm{mg}$; tiamina $-2.000 \mathrm{mg}$; riboflavina $-6.000 \mathrm{mg}$; piridoxina - $4.000 \mathrm{mg}$; cianocobalamina - $20.000 \mu \mathrm{g}$; ácido nicotínico $40.000 \mathrm{mg}$; ácido pantotênico - $12.000 \mathrm{mg}$; biotina - $150 \mathrm{mg}$; ácido fólico $1.000 \mathrm{mg}$; selênio $-250 \mathrm{mg}$; veículo q.s.p. $-1.000 \mathrm{~g}$.

${ }^{2}$ Quantidade por kg de produto:manganês - $160.000 \mathrm{mg}$; ferro - $100.000 \mathrm{mg}$; zinco $-100.000 \mathrm{mg}$; cobre $-20.000 \mathrm{mg}$; cobalto $-2.000 \mathrm{mg}$; iodo $-2.000 \mathrm{mg}$; veículo q.s.p. $-1.000 \mathrm{~g}$.

Os três ensaios de metabolismo foram projetados em delineamento inteiramente casualizado, com cinco tratamentos e quatro repetições, para as análises estatísticas foi utilizado o Sistema de Análises Estatísticas e Genéticas - SAEG, versão 9,0.

Cada ensaio teve duração de sete dias, sendo três de adaptação das aves às dietas experimentais e às gaiolas metabólicas e quatro dias de coleta total de excretas.

Ao término do período experimental, foram quantificadas a ração consumida e a excreta produzida durante os quatro dias de coleta. Posteriormente, as amostras de excretas foram descongeladas, pesadas, homogeneizadas e uma amostra representativa de cada repetição foi retirada para as análises laboratoriais. Estas alíquotas passaram por présecagem em estufas ventiladas a $55^{\circ} \mathrm{C}$ por 72 horas. Após a pré-secagem as amostras foram moídas e acondicionadas em recipentes plásticos para posteriores análises de matéria seca, energia bruta em bomba calorimétrica (modelo Parr 1261) e o nitrogênio pelo método da combustão direta de Dumas via aparelho automatizado LECO.

Uma vez obtidos os resultados das análises laboratoriais dos alimentos, da ração-referência e das excretas, foram calculados os valores de energia metabolizável aparente corrigida pelo balanço de nitrogênio (EMAn) para cada tipo de milho por meio das equações propostas por Matterson et al. (1965).

As equações propostas por Janssen et al. (1989) e Rodrigues et al. (2001), foram estimadas a partir da composição química dos alimentos e a equação proposta por Rostagno et al. (2005) a partir dos parâmetros físicos.

\section{Resultados e Discussão}

Nos três ensaios metabólicos, os valores de energia metabolizável aparente superaram os de energia metabolizável aparente corrigida (Tabela 2) indicando balanço positivo de nitrogênio, não ocorrendo perda de peso e degradação de tecido muscular. Assim, os valores de energia do nitrogênio retido foram descontados da energia aparente para obtenção dos valores da energia metabolizável aparente corrigida; em consequência, o valor de EMA dos alimentos foi superior ao valor de energia metabolizável aparente corrigida. De acordo com Leeson \& Summers (2001) e Nunes et al. (2006), é necessário corrigir os valores estimados de energia pelo balanço de nitrogênio, pois, durante um ensaio de metabolismo, é impossível assegurar que todas as aves apresentem a mesma taxa de crescimento, tornando-se necessária a correção para o balanço de nitrogênio.

Estudando valores de energia metabolizável aparente e da aparente corrigida do glúten de milho para frangos de corte em duas idades, Brumano et al. (2006) encontraram

Tabela 2 - Valores de energia metabolizável aparente e aparente corrigida dos milhos de diferentes densidades em diferentes fases de criação de frangos de corte (com base na matéria natural)

\begin{tabular}{|c|c|c|c|c|c|c|}
\hline \multirow[t]{2}{*}{ Tipo de milho } & \multicolumn{3}{|c|}{ EMA, kcal/kg } & \multicolumn{3}{|c|}{ EMAn, kcal/kg } \\
\hline & Inicial & Crescimento & Final & Inicial & Crescimento & Final \\
\hline Alta densidade & 3.593 & 3.688 & 3.709 & 3.562 & 3.576 & 3.610 \\
\hline Densidade baixa & 3.299 & 3.339 & 3.388 & 3.198 & 3.229 & 3.354 \\
\hline Densidade original & 3.428 & 3.512 & 3.634 & 3.357 & 3.416 & 3.585 \\
\hline Média & 3.450 & 3.548 & 3.588 & 3.375 & 3.444 & 3.526 \\
\hline
\end{tabular}


valores superiores nas aves com idade mais avançada. Os valores de energia metabolizável aparente e da aparente corrigida na fase de 21 a 30 dias de idade, com base na matéria natural foram, respectivamente, 3.726 e $3.608 \mathrm{kcal} / \mathrm{kg}$ e para a fase de 41 a 50 dias, 4.138 e $4.013 \mathrm{kcal} / \mathrm{kg}$, respectivamente.

No ensaio realizado com frangos na fase inicial, os valores obtidos foram menores, tanto para a energia metabolizável aparente quanto para a energia metabolizável aparente corrigida, em comparação aos ensaios realizados nas fases de crescimento e final. As diferenças nos valores de energia metabolizável dos alimentos, em função da idade, podem ser explicadas por dois motivos: o primeiro é que animais mais velhos apresentam menores taxas de passagem permitindo maior tempo de permanência dos nutrientes no trato gastrintestinal sob a ação das enzimas digestivas (Burnell et al.1990); o segundo seria a reduzida eficiência com que aves jovens digerem as gorduras, proteínas, amido (Larbier \& Leclerc, 1994) devido à imaturidade do sistema digestivo.

Segundo Batal \& Parsons (2002), a necessidade de desenvolvimento e de maturação do sistema digestório em aves jovens pode influenciar na utilização dos nutrientes dos alimentos, reduzindo os valores de energia metabolizável, especialmente nos 10 primeiros dias após a eclosão. Esses autores determinaram que o valor de energia metabolizável de uma ração à base de milho e farelo de soja aumenta até o 14 o dia de idade das aves, sendo este fato devido ao melhor aproveitamento dos nutrientes com o avanço da idade.

De acordo com Nir (1998), os valores de EMAn de alimentos encontrados em tabelas da literatura estão acima dos valores corretos para pintos na primeira semana. Corroborando, Menten et al. (2002) encontraram valores de energia metabolizável do milho e do farelo de soja na fase pré-inicial inferiores aos valores propostos na literatura, evidenciando a deficiência dos processos digestivos e absortivos das aves de 1 a 7 dias de idade.
Neste trabalho, o milho de alta densidade teve maior valor de EMAn, seguido pelos milhos de densidade intermediária, média e baixa respectivamente. Tendo a EMAn uma variação de 3.562 a $3.198 \mathrm{kcal} / \mathrm{kg}$ para aves de 14 a 17 dias de idade, variações 3.576 a $3.229 \mathrm{kcal} / \mathrm{kg}$ no estudo das aves com 25-28 dias de idade e variações de 3.610 a $3.354 \mathrm{kcal} / \mathrm{kg}$ para aves de 38 a 41 dias de idade. Resultados semelhantes foram encontrados por Silva et al. (2008), que, estudando os valores energéticos para milhos de diferentes qualidades determinados com frangos de corte, verificaram que o milho de alta densidade foi energeticamente superior ao de densidade intermediária e ao de baixa densidade, cerca de, respectivamente 6,0 e $12,5 \%$ com frangos de 11 a 19 dias de idade.

As diferenças encontradas nos valores de energia metabolizável aparente e da energia metabolizável aparente corrigida podem ser utilizados para classificar os alimentos em alta energia e baixa energia. Esta classificação pode estar relacionada à composição das frações de milho obtidas pela mesa densimétrica, pois alimentos com maior concentração de amido possuem maiores valores de EMA; em contrapartida, aqueles com maior teor de polissacarídeos não-amiláceos têm menores valores de EMAn. As diferenças entre os valores de energia estimados com aves em diferentes idades apresentados neste trabalho reforçam a teoria de que é necessário determinar a energia dos alimentos de acordo com a categoria animal para que as aves possam melhor utilizá-los, contribuindo para melhor eficiência alimentar e redução dos custos de produção.

Os resultados das análises bromatológicas e a energia metabolizável aparente corrigida dos milhos de diferentes densidades (Tabela 3) foram utilizados para estimar os valores de energia metabolizável aparente corrigida de acordo com equações de predição descrita na literatura. Quando comparados os valores encontrados para os milhos de diferentes densidades aos dados da literatura, tanto nas tabelas nacionais (Rostagno et al., 2005; EMBRAPA, 1991) quanto em tabela estrangeira (NRC 1994), há variações

Tabela 3 - Composição química e valores de energia dos milhos de diferentes densidades expressos na matéria natural

\begin{tabular}{|c|c|c|c|c|}
\hline \multirow[b]{2}{*}{ Valor nutricional } & \multicolumn{4}{|c|}{ Tipo de milho } \\
\hline & Alta densidade & Intermediária densidade & Baixa densidade & Densidade original \\
\hline EMAn-inicial, kcal/kg & 3.562 & 3.382 & 3.198 & 3.357 \\
\hline EMAn-final, kcal/kg & 3.610 & 3.554 & 3.354 & 3.585 \\
\hline Matéria seca, \% & 86,89 & 86,44 & 86,46 & 86,75 \\
\hline Proteína bruta, \% & 8,84 & 9,23 & 8,95 & 8,80 \\
\hline Matéria mineral, \% & 1,07 & 1,11 & 1,42 & 1,10 \\
\hline Extrativo não-nitrogenado, \% & 70,61 & 69,63 & 69,92 & 70,37 \\
\hline Amido, \% & 57,75 & 54,91 & 50,93 & 53,83 \\
\hline
\end{tabular}


entre os valores da composição química dos milhos (milho de densidade alta, milho de densidade intermediária, milho de densidade baixa e milho de densidade original) com os daquelas referências. Essas variações podem ser causadas por vários fatores, entre eles, o material genético, a diferença entre solos, o clima e os tipos de armazenamento.

Os valores da proteína bruta nos milhos de diferentes densidades variaram em até 4,65\% (8,80 a 9,23\%). O teor de proteína bruta dos milhos de diferentes densidades foi superior ao citado na tabela de Rostagno et al. (2005). Segundo Kato (2005), a forma e a frequência com que são realizadas as adubações nitrogenadas influencia os teores de proteína bruta do grão de milho, devido ao aumento da zeína, que é uma proteína de baixo valor nutricional. Entretanto, este fator pode ser desconsiderado, uma vez que esses milhos receberam a mesma adubação e tratos culturais. É possível que esta variação seja devida à própria característica do grão.

O valor do extrato etéreo dos milhos foi superior ao reportado por Rostagno et al. (2005), exceto para o milho de baixa densidade, cujo valor foi muito semelhante, porém todos os milhos apresentaram valores inferiores ao valor citado por estes autores para o milho de alta gordura, de $6,40 \%$.

Houve redução expressiva do percentual de amido nos milhos à medida que a densidade diminuiu. A porcentagem de amido no milho de densidade alta foi $12 \%$ superior à observada no milho de densidade baixa, sugerindo eficiência da mesa densimétrica em segregar milho com diferentes porcentagens de amido. É importante observar que este aumento no teor do amido no milho de densidade alta frente ao milho de densidade baixa ( 57,75 vs $50,93 \%)$ contribuiu para que o milho de densidade alta tivesse em média um aumento na energia metabolizável aparente corrigida de $230 \mathrm{kcal} / \mathrm{kg}$ de milho.

Os resultados da classificação das frações de milho de acordo com os padrões do Ministério da Agricultura, Pecuária e Abastecimento estão demonstrados a seguir (Tabela 4).

De acordo com a classificação, houve maior incidência de grãos ardidos, carunchado, quebrados, material estranho e impurezas no milho de baixa densidade e no milho de densidade intermediária. À medida que a qualidade do milho diminui, as perdas aumentam (Tabela 2). Esse resultado está em consonância com o valor de energia metabolizável obtido nos ensaios de metabolismo, onde se verificou que a energia determinada para o MDB foi em média 9\% inferior ao MDA. Dale (1996) reportou que as matérias estranhas e os grãos quebrados reduzem o valor da energia metabolizável verdadeira para aves em 300 e $90 \mathrm{kcal} / \mathrm{kg}$ respectivamente. A partir destes resultados, verifica-se a necessidade de se realizarem correções para o milho de acordo com sua qualidade avaliada pela classificação de grãos. Verifica-se que, à medida que a qualidade do milho diminui, as perdas aumentam.

O valor energético das frações de milho foram estimadas com base na equação de predição (Rostagno et al., 2005), $\mathrm{EMp}=-0,064+1,62 \mathrm{QBR}+6,98 \mathrm{FRIM}+10,06 \mathrm{FUN}+12,28$ INS + 5,87 ADC, sendo: EMp: Energia metabolizável de perdas, $\mathrm{QBR}=$ grãos quebrados em \%; FRIM = fragmentos de grãos e impurezas em \%; FUN = grãos atacados por fungos em \%; INS = grãos atacados por insetos em \% e $\mathrm{ADC}=$ grãos atacados por diversas causas em \%. Essa equação considera o milho padrão ótimo tendo $3.432 \mathrm{kcal}$ $\mathrm{EM} / \mathrm{kg}$. Os valores obtidos foram de 3.426, 3.403, 3.341 e $3.389 \mathrm{em} \mathrm{kcal} / \mathrm{kg}$, respectivamente para milho de densidade alta, milho de densidade intermediária, milho de densidade baixa e milho de densidade original.

De acordo com a classificação das frações de milho foram estimados os valores de EMAn, segundo a equação de predição obtida por Rodrigues et al. (2001), EMAn = 4354,8 - 112,05FB - 151,74MM $\left(\mathrm{R}^{2}=0,95\right)$. Os valores estimados foram 3.944, 3.936, 3.882, $3.934 \mathrm{kcal} / \mathrm{kg}$, respectivamente, para milho de densidade alta, milho de densidade intermediária, milho de densidade baixa e milho de densidade original. Utilizando os resultados obtidos da proteína bruta, extrato etéreo e extrativo não nitrogenado foram estimados os valores da EMAn de acordo com a equação proposta por Janssen et al. (1989): EMAn = 36,21PB + 85,44EE + 37,26ENN, os valores encontrados foram $3.306 \mathrm{kcal} / \mathrm{kg}$ para o MDA, $3.291 \mathrm{kcal} / \mathrm{kg}$ para MDI, $3.260 \mathrm{kcal} / \mathrm{kg}$ para MDB e $3.302 \mathrm{kcal} / \mathrm{kg}$ para o MDO.

Tabela 4 - Classificação das frações de milho estratificado

\begin{tabular}{lcccc}
\hline & & \multicolumn{2}{c}{ Tipo de milho } \\
\cline { 2 - 5 } Classificação & Alta densidade & Densidade intermediária & Baixa densidade & Densidade original \\
\hline Bom (\%) & 98 & 95,6 & 77,71 \\
Ardido (\%) & 0,5 & 2,61 & 5,22 & 91,26 \\
Carunchado (\%) & - & - & 0,34 & 0,0 \\
Quebrado (\%) & 1,5 & 1,79 & 15,3 & 4,98 \\
Material estranho + impurezas (\%) & - & - & 1,43 \\
\hline
\end{tabular}


Os resultados de densidade (peso específico) dos milhos estratificados pela mesa gravimétrica, logo após a estratificação e após 16 meses de armazenamento utilizando o método do peso hectolitro pode ser observado abaixo (Tabela 5).

De acordo com os dados observados acima, o milho de alta densidade apresentou maior $(\mathrm{P}<0,05)$ densidade logo após a segregação e durante todo o período de armazenamento. Os valores encontrados ao longo do tempo para os milhos de densidade original e intermediária não diferiram $(\mathrm{P}<0,05)$ entre si, e o milho de baixa densidade teve menor valor em g/L, que foi em média 7\% inferior ao do milho de mais alta densidade. Após o período total de armazenamento, o MDA teve perda em $\mathrm{g} / \mathrm{L}$ maior $(\mathrm{P}<0,05)$ que a perdida pelo milho de baixa densidade; e essa maior perda pode ser explicada pela composição dos milhos, pela menor perda na densidade do MDB em g/L ao longo do período de armazenamento, quando comparados às perdas dos demais milhos, pode ser explicada pelo fato do MDB ter apresentado menor percentual de amido, tendo menor quantidade de substrato para ser oxidado e estas reações de oxidação levam a diminuição dos teores de energia, proteínas e vitaminas lipossolúveis, contribuindo para perda de peso do grão. E também pelo fato de que os insetos consomem principalmente os carboidratos dos grãos, diminuindo o seu valor energético e levando uma perda na densidade de milho que possuí maior proporção de amido.

Utilizando os valores das densidades dos diferentes tipos de milhos estratificados obtidos através de balança de peso hectolitro foi determinada uma equação para estimava da energia metabolizável aparente corrigida, para frangos de corte: $\mathrm{EMAn}=4,8487 \mathrm{x}-495,83\left(\mathrm{R}^{2}=0,93\right)$, em que x é o valor do peso hectolítrico (PH) em g/L. Os valores estimado segundo essa equação foram: 3471, 3375, 3134 e $3353 \mathrm{kcal} / \mathrm{kg}$ respectivamente para MDA, MDI, MDB e MDO. Silva et al. (2006), estudando as densidades de milhos de diferentes densidades, verificaram que a média da densidade para o MDA foi 9,3 e 35,8\% superior às densidades observadas para o MDI e o MDB, respectivamente. Esses resultados demonstram a importância de realizar correções no milho antes de empregá-lo nas formulações.
As equações para estimativa da EMAn dos diferentes autores (Rostagno et al., 2005; Rodrigues et al., 2001; Janssen, 1989) e a equação desenvolvida neste trabalho foram comparadas àqueles valores obtidos diretamente no ensaio de metabolismo na fase de crescimento, conforme pode ser observado nas Figuras 1, 2, 3 e 4.

A equação proposta por Rostagno et al. (2005) não possibilitou detectar bem as diferenças entre os milhos de diferentes qualidades, enquanto a equação desenvolvida neste trabalho foi mais sensível em detectar as diferenças entre os milhos. Esta equação pode tornar as formulações mais precisas, contribuindo para obtenção de uma ração de custo mínimo, além de ser de rápida determinação.

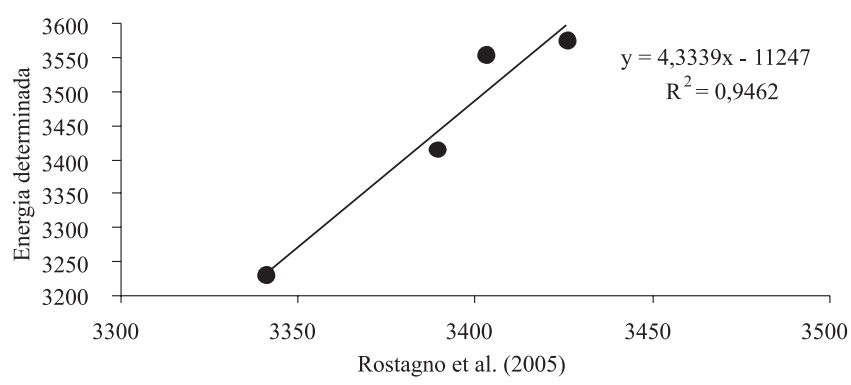

Figura 1 - Energia estimada por Rostagno et al. (2005) e energia determinada no ensaio de metabolismo.

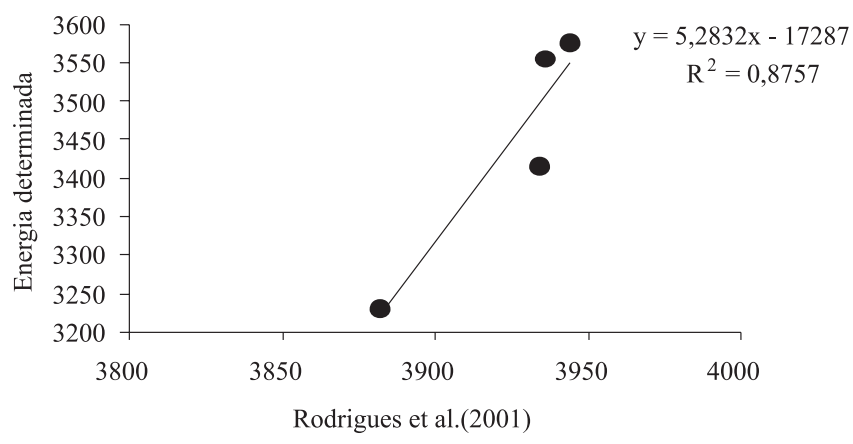

Figura 2 - Energia estimada por Rodrigues et al. (2001) e energia determinada no ensaio de metabolismo.

Tabela 5 - Variação das densidades dos milhos estratificados de diferentes densidades ao longo do tempo (meses), em g/L

\begin{tabular}{lccccc}
\hline Milho & \multicolumn{4}{c}{ Medidas realizadas no tempo (meses) } \\
\cline { 2 - 6 } & Maio/2007 & Dezembro/2007 & Junho/2008 & Agosto/2008 & Setembro/2008 \\
\hline Milho de densidade alta & $818,1 \mathrm{a}$ & $818,6 \mathrm{a}$ & $781,4 \mathrm{a}$ & $760,6 \mathrm{a}$ & $759,5 \mathrm{a}$ \\
Milho de densidade intermediária & $798,3 \mathrm{~b}$ & $796,3 \mathrm{~b}$ & $742,5 \mathrm{~b}$ & $736,8 \mathrm{bc}$ & $733,5 \mathrm{~b}$ \\
Milho de densidade baixa & $748,7 \mathrm{c}$ & $745,3 \mathrm{c}$ & $730,2 \mathrm{~b}$ & $727,8 \mathrm{c}$ & $717,9 \mathrm{c}$ \\
Milho de densidade original & $793,7 \mathrm{~b}$ & $793,8 \mathrm{~b}$ & $743,3 \mathrm{~b}$ & $742,4 \mathrm{~b}$ & $740,0 \mathrm{~b}$ \\
\hline
\end{tabular}

a, b, c = Médias seguidas por letras diferentes na coluna diferem $(\mathrm{P}<0,05)$ entre si pelo teste de Tukey. 


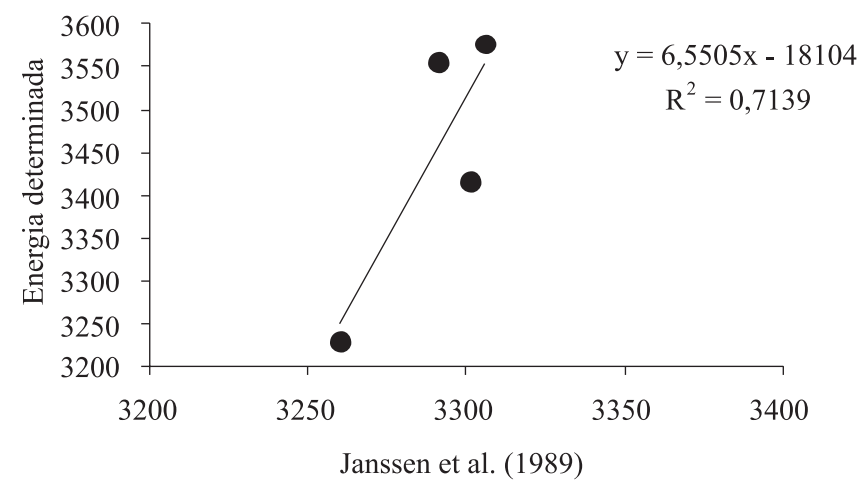

Figura 3 - Energia estimada por Janssen et al.(1989) e energia determinada no ensaio de metabolismo.

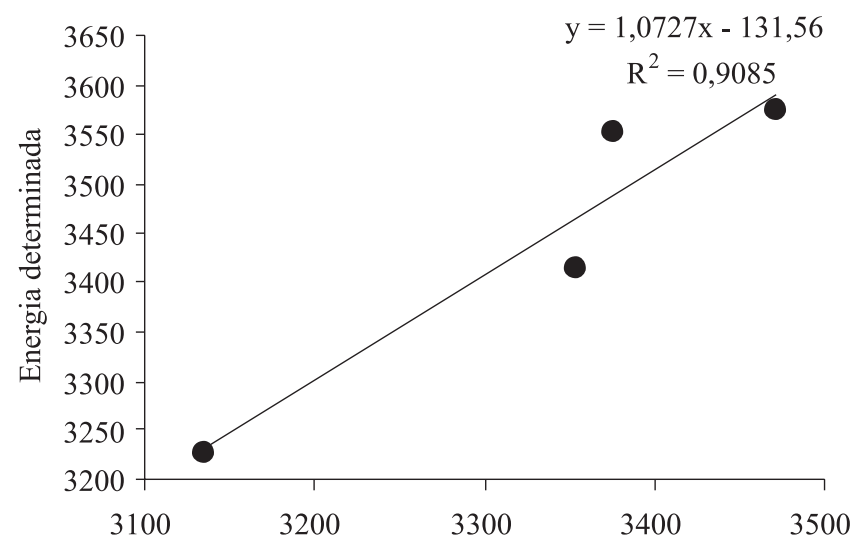

Valores de energia obtidos por equação gerada neste trabalho

Figura 4 - Energia estimada por equação de predição desenvolvida neste trabalho e energia determinada no ensaio de metabolismo.

A equação proposta por Rodrigues et al. (2001), que utiliza PB e a FB como variáveis independentes, não se mostrou adequada para predizer os valores de EMAn. A cada variação de uma unidade no valor da energia estimada, observa-se uma variação de cinco unidades no valor da determinada. A equação de Janssen (1996) foi inadequada para predição dos valores de EMAn para milho de diferentes qualidades, verificando uma variação de 6,5 para a energia determinada para cada uma variação na energia estimada, o que nos permite inferir que esta equação não é segura pra estimar valores energéticos de milho para frangos de corte.

\section{Conclusões}

A energia metabolizável pode variar entre milhos de diferentes densidades. Milhos de densidade alta apresentam maior valor, seguidos daqueles de densidade intermediária e de densidade original e, por último, pelos de baixa densidade para todas as idades estudadas. Entre as equações de predição utilizadas para estimar valor energético de milho para frangos de corte, a equação que considera o peso hectolítrico apresenta melhor ajuste para estimar valor de energia metabolizável aparente corrigida aparente.

\section{Referências}

BATAL, A.B.; PARSONS, C.M. Effects of age on nutrient digestibility in chicks fed different diets. Poultry Science, v.81, p.400-407, 2002.

BRUMANO, G.; GOMES, P.C.; ALBINO, L.F.T. et al. Composição química e valores de energia metabolizável de alimentos protéicos determinados com frangos de corte em diferentes idades. Revista Brasileira de Zootecnia, v.35, n.6, p.2297-2302, 2006.

BURNELL, T.W.; CROMWEL, G.L.; STAHLY, T.S. Effects of particle size on the biological availability of calcium and phosphorus in defluorinated phosphate for chicks. Poultry Science, v.69, p.1110-1117, 1990.

DALE, N. Efeitos da qualidade no valor nutritivo do milho. In: CONFERÊNCIA APINCO CIÊNCIA E TECNOLOGIA AVÍCOLA. Anais... Campinas: FACTA, 1996. p.67-72.

EMPRESA BRASILEIRA DE PESQUISA AGROPECUÁRIA EMBRAPA. Centro Nacional de Pesquisa de Suínos e Aves. Tabela de composição química e valores de energéticos de alimentos para suínos e aves. Concórdia: EMBRAPACNPSA, 1991. 97p.

JANSSEN, W.M.M.A. European table of energy values for poultry feedstuffs. 3.ed. Beekbergen, 1989. 84p. (Spelderholt Center for Poultry Research and Information Services).

GREGG, B.R.; FAGUNDES, S.R.F. Manual de operações da mesa de gravidade, Zampronio: Editora, 2005. p78.

KATO, R.K. Energia metabolizável de alguns ingredientes para frangos de corte em diferentes idades. 2005. 96f. Tese (Doutorado em Zootecnia) - Universidade Federal de Lavras, Lavras.

LARBIER, M.; LECLERCQ, B. Nutrition and feeding of poultry. Nottingham: Nottingham University Press, 1994. 305p.

LEESON S.; SUMMERS, J.D. Scott's nutrition of the chicken. 4.ed. Guelph: University Books, 2001. 591p.

MINISTÉRIO DA AGRICULTURA, PECUÁRIA E ABASTECIMENTO - MAPA. Disponível em: <http://www.agricultura.gov.br>. Acesso em: 14/01/2009.

MATTERSON, L.D.; POTTER, L.M.; STUTZ, N.W. et al. The metabolizable energy of feed ingredients for chickens. Agricultural Experiment Station Research Report, v.7, p3-22, 1965.

MENTEN, J.F.M.; LONGO, F.A.; PEDROSO, A.A. et al. Valores de energia metabolizável de milho e farelo de soja para frangos de corte na fase pré-inicial. In: REUNIÃO ANUAL DA SOCIEDADE BRASILEIRA DE ZOOTECNIA, 39., 2002, Recife. Anais... Recife: SBZ, 2002. p.210-214.

NIR, I. Mecanismos de digestão e absorção de nutrientes durante a primeira semana. In: CONFERÊNCIA APINCO 98 DE CIÊNCIA E TeCnOlOGiA AVÍCOlAS, 1998, Campinas. Anais... Campinas: Facta, 1998. p.81-91.

NATIONAL RESEARCH COUNCIL - NRC. Nutrient requirements of poultry. Washington, D.C.: National Academy Press, 1994. 176p. 
NUNES, R.V. Valores energéticos de diferentes alimentos de origem animal para aves. Revista Brasileira de Zootecnia, v.35, n.4, p.1752-1757, 2006 (supl.).

RODRIGUES, P.B.; ROSTAGNO, H.S.; ALBINO, L.F.T. Valores energéticos do milheto, do milho e subprodutos do milho, determinados com frangos de corte e galos adultos. Revista Brasileira de Zootecnia, v.30, n.64, p.767-1778, 2001.

ROSTAGNO, H.S. Tabelas brasileiras para aves e suínos: composição de alimentos e exigências nutricionais. 2.ed. Viçosa, MG: UFV, Departamento de Zootecnia, 2005. 186p.
SILVA, C.S.; COUTO, H.P.; FERREIRA, R.A. et al. Valores nutricionais de milho de diferentes qualidades para frangos de corte. Revista Brasileira de Zootecnia, v.37, n5, p.883-889, 2008.

SILVA, D.J. Análises de alimentos (Métodos químicos e biológicos) 2.ed. Viçosa, MG: UFV, 1990. p.166.

UNIVERSIDADE FEDERAL DE VIÇOSA - UFV. Sistema de análise estatísticas e genéticas - SAEG. Versão 9,0. Viçosa, MG: UFV, 2001. 301p. 